\title{
TV-video observations of bed and basal sliding on Storglaciären, Sweden
}

\author{
Veijo Allan Pohjola \\ Institutionen för Geovetenskap, Uppsala Universitet, 75122 Uppsala, Sweden
}

\begin{abstract}
Four boreholes in Storglaciären, a small valley glacier in northern Sweden, were inspected with a video camera. In two of the boreholes, the apparent glacier bed was filmed. In one borehole, the bed was found to be composed of soft sediment, but in the other it consisted of bedrock. In the latter, the camera moved $5.6 \mathrm{~mm}$ relative to the bed during an $80 \mathrm{~min}$ period. The recorded camera movement showed a background motion which is in the expected range of basal sliding. Superimposed on the background motion, a jerky motion of a high-speed spike was found. The jerky motion is interpreted as a stress release induced by local topography at the ice-bed interface.
\end{abstract}

\section{INTRODUCTION}

Storglaciären, situated in the Kebnekaise Massif, Swedish Lappland, is considered to be a temperate valley glacier with a perennial cold surface zone in its ablation area (Holmlund and Eriksson, 1989). Seismic and radio-echo investigations have been used to map the bed topography (Schytt, 1962; Björnsson, 1981; paper in preparation by M. G. Eriksson, H. Björnsson, U.C. Herzfeld and P. Holmlund). This has revealed that the underlying bedrock is formed as a series of overdeepenings with intervening riegels. A major part of the ablation area is situated over the largest overdeepening, and much of the work on Storglaciären has been concentrated in this part of the glacier.

Recent work on Storglaciären includes boreholedeformation studies (Hooke and others, 1987; paper in preparation by R.LeB. Hooke, V.A. Pohjola, E.P. Jansson and J. Kohler), strain analysis to reveal force balance in selected parts of the glacier (Hooke and others, 1989), comparisons of the response in emergence velocity to a change in mass balance (Holmlund, 1988), diurnal tilts of the ice surface (Jansson and Hooke, 1989) and studies of the subglacial drainage (Hooke and others, 1988, 1990).

These studies all stress the importance of knowing what kind of bed there is under the glacier. Whether the glacier rests upon bare bedrock or on deformable sediments will have a significant influence on the interpretation of borehole-deformation studies, studies of the glacial hydrology, etc.

Many methods have been used to reveal what lies hidden beneath the ice. Geophysical techniques, such as seismic (Blankenship and others, 1987) and geo-electrical methods (Haeberli and Fisch, 1984), give indirect information averaged over wide areas of the bed. More direct techniques of in situ investigation, through either natural passages (Theakstone, 1979), Man-made tunnels (Hagen and others, 1983; Hagen, 1986; Boulton and Hindmarsh, 1987; Echelmeyer and Zhongxiang, 1987), or more typically, grab sampling in boreholes, all reveal information about a specific location.

In the latter category is the technique of viewing the bed through a camera lowered down a borehole. Both photographic single-shot and TV cameras have been used (Harrison and Kamb, 1973; Engelhardt and others, 1978; Koerner and others, 1981). While photographic cameras give clearer pictures, TV cameras are more useful because they can be monitored directly and, by this, placing the operator in an instantaneous decisive position of what to focus at. Another advantage of the TV technique is the possibility of recording a continous flow of images on a video recorder, which is a useful tool for further analyses of the information.

\section{METHOD AND OBSERVATIONS OF THE BED}

Basal conditions at Storglaciären have been previously explored using a variety of techniques (Schytt, 1962, unpublished; Walford and others, 1986). Brand and others (1987) used electrical resistivity techniques to infer an $0.4-0.7 \mathrm{~m}$ thick layer of low-resistive, fine-grained till c. $200 \mathrm{~m}$ north of borehole $89: 4$ (see Fig.1). Seismic surveys showed that the bed in the area of the major overdeepening consists of a mixture of seismically hard and soft material (paper in preparation by J. Paetz and R. LeB. Hooke).

The picture that emerges from the earlier studies of the subglacial conditions is that of a bed consisting of bedrock covered with a veneer of sediment. To corroborate these findings, a colour video camera was used to inspect the bed at the bottom of boreholes.

The video camera was specially designed for inspec- 


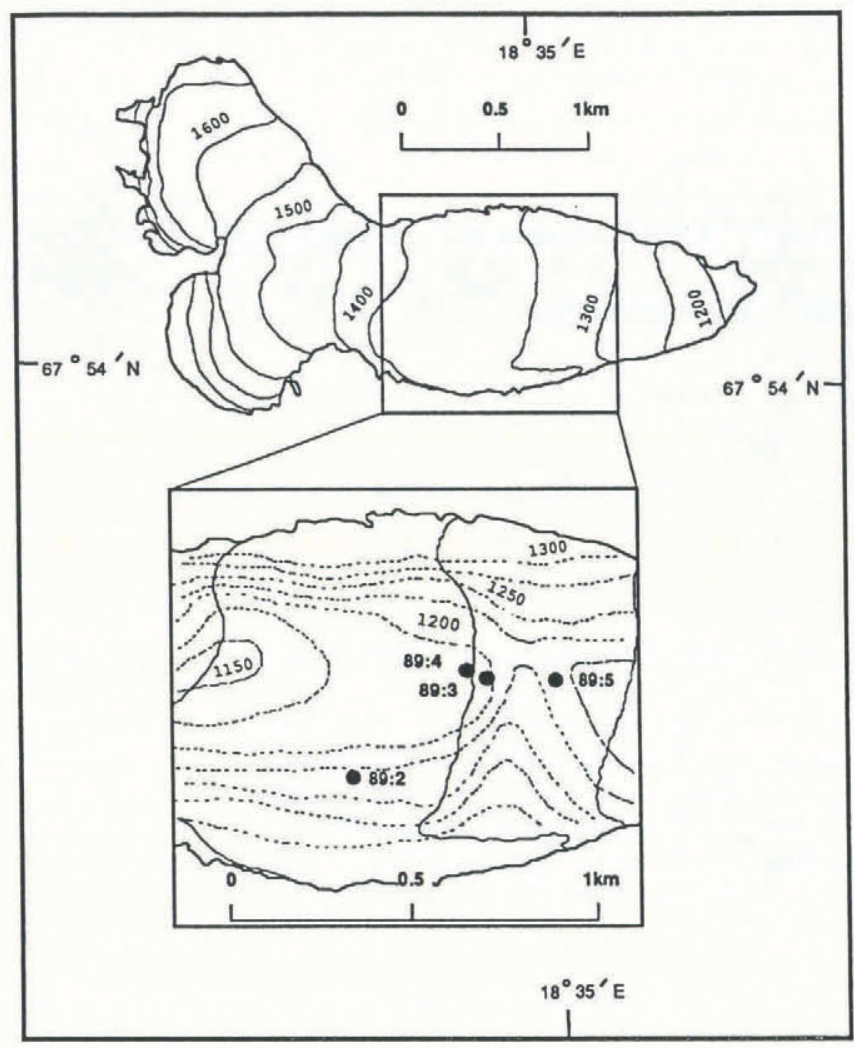

Fig. 1. Storglaciären with the boreholes inspected with a video camera in 1989. Surface topography from Holmlund (1987). Bed topography shown in inset after Björnsson (1981).

tions of pipelines and sewers. Encapsulated in a steel pressure chamber with a glass viewing bubble, the camera was mounted so that it could be moved about within the chamber. This construction gave the camera nearly hemispherical viewing coverage, with a rotation of more than $220^{\circ}$ in the horizontal plane and up to $85^{\circ}$ in the vertical plane. The lowering and hoisting of the camera in the borehole was managed manually with a cable wheel

Table 1. Borehole data

Borehole $\begin{gathered}\text { Date } \\ \text { drilled }\end{gathered} \quad$ Depth $\begin{gathered}\text { Date } \\ \text { inspected }\end{gathered} \quad \begin{gathered}\text { Hydraulic } \\ \text { head }^{1}\end{gathered}$

$\mathrm{m}$

$\mathrm{m}$

$\begin{array}{lllll}89: 2 & \text { 14 Jul 1989 } & \text { 129 } & \text { 17 Jul 1989 } & 125.5 \\ 89: 3^{2} & \text { 18 Jul 1989 } & 162 & \text { 18 Jul 1989 } & 152 \\ 89: 3^{3} & \text { 19 Jul 1989 } & \text { 162.5 } & \text { 29 Jul 1989 } & 144^{4}\end{array}$

\footnotetext{
${ }^{1}$ Hydraulic head is the height of the water column in the borehole during the inspection.

${ }^{2}$ Bed was not reached.

${ }^{3}$ Re-drilled $0.5 \mathrm{~m}$.

${ }^{4}$ Water level rose $0.4 \mathrm{~m}$ during the inspection (0830 to $1100 \mathrm{~h})$.
}

at the surface. A ring of lights was mounted around the viewing bubble. The light power and movement of the camera were controlled from a computer unit at the surface. A frame was made to hold a ruler below the camera, and hence serve as a scale. The pressure chamber had an outer diameter of $8 \mathrm{~cm}$ and the lamp crest had a diameter of $13 \mathrm{~cm}$.

Four holes were drilled during the summer of 1989 using standard hot-water drilling techniques. The boreholes were left undisturbed for a period of time after drilling to give suspended sediment time to settle (see Table 1). The camera was then slowly lowered into the hole until it reached the bottom of the borehole. Many englacial structures were seen during lowering but description of those are beyond the scope of this paper and they will be discussed elsewhere. The bed was observed in only two of the boreholes. The camera was prevented from reaching the bed by a narrow waist in one borehole and an englacial boulder in another borehole. Table 1 gives data on the two boreholes where the bed was observed and Figure 1 shows their location.

\section{Bed observations in borehole 89:2}

The water in the borehole was clear in the upper parts but became gradually cloudier from a depth of $75 \mathrm{~m}$. Visibility was very limited from $118 \mathrm{~m}$ down to the bed. During lowering of the camera, thin curtains of upwelling sediments were seen. The thickness of these curtains increased with depth. At the bed, the viewing glass of the pressure chamber sank into soft sediments. After a short time of inspection, the camera was lifted several meters. A glob of the bed sediment had stuck to the viewing glass and was washed off during lifting of the camera from the bed. The bed appeared to consist of fine sand-sized particles in a silty matrix. Figure $2 \mathrm{a}$ shows the moment when the camera was gently lifted from the bed.

\section{Bed observations in borehole 89:3}

Cloudy water was encountered abruptly at an englacial channel $30 \mathrm{~m}$ above the bed. There was very low visibility within $5 \mathrm{~m}$ of the bed due to the upwelling sediments. The camera hit the bed with a bounce, and a thin veil of fines, slightly covering the undoubtedly hard surface, was forced into suspension. Due to the low visibility, the camera had to be close to the bed while inspecting. This implied that only the area immediately below the camera could be viewed. The observed bed showed a slightly undulating surface with some coarser fractions on it (see Fig. 2b). Comparisons with surface structures of an englacial boulder of amphibolitic character found in borehole 89:5 showed that the viewed bed in borehole 89:3 had the same texture as the boulder in borehole 89:5. The bed in borehole 89:3 was found by this method to be composed of rock of the same kind. Comparisons of the micro-relief on exposed amphibolitic boulders from the retreating glacier front with the observed relief from the video strengthened this conclusion.

\section{Discussion of the bed character}

The bed must have been disturbed to some degree by the 


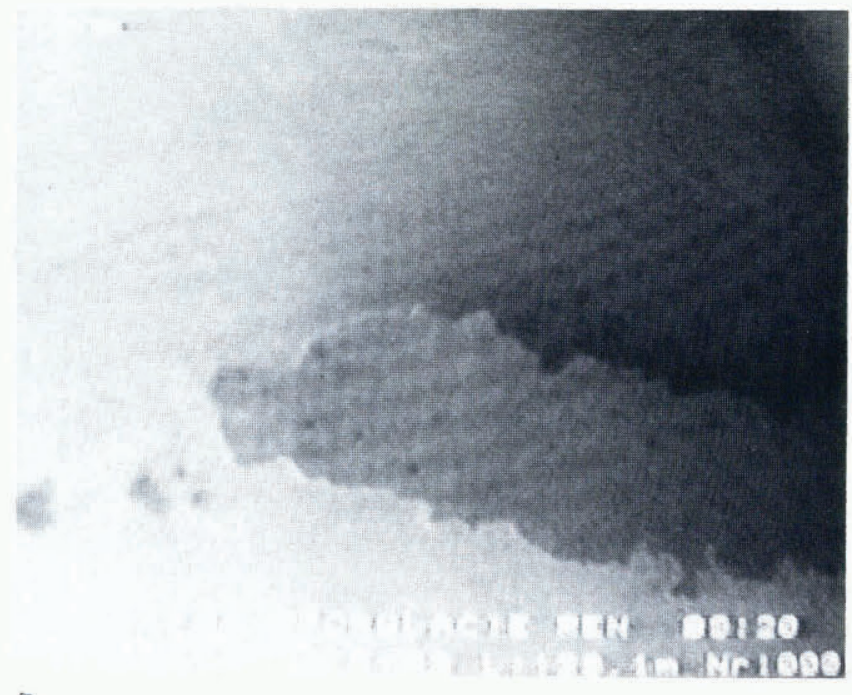

a

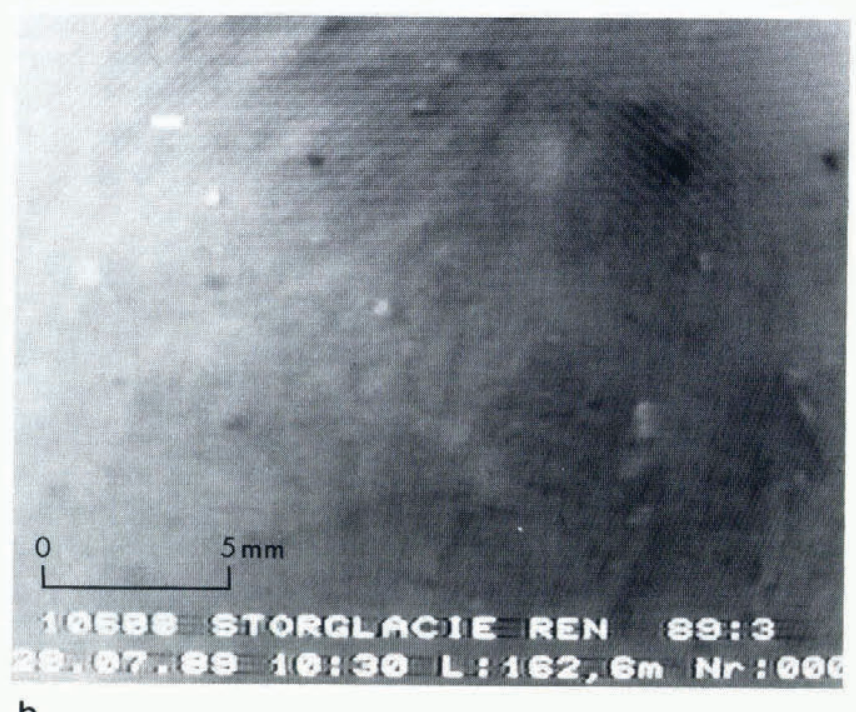

b

Fig. 2. Images from the inspection of the bed photographed from the TV monitor. a. Borehole 89:2. This image shows the bed just when the camera was raised. The irregular somewhat darker field in the middle of the image is the glob of sediment which stuck to the viewing glass of the camera. The scale is approximately the same as in Figure $2 b . b$. Borehole 89:3. The image shows the rock bed over which the camera hung during the velocity measurements. The visible geometrical structures are larger mineral grains in the rock.

hot-water jet in the process of drilling the borehole. How does such disturbance affect what is seen through the camera? If there is no water movement at the bottom of a borehole, then any sediment driven into suspension would gradually settle out after the drill is removed. This would result in a dilated graded deposit overlying the compacted layers of the original, undisturbed bed material, a deposit that might also result from fall-out of englacial sediments released during drilling. However, if the borehole were connected to a subglacial drainage network, originally existing or opened by the drill, then it is possible that the disturbed sediments would be flushed away. Taken to its extreme, this would result in stripped bedrock.

Principally, if the time between drilling and inspection was long enough, it is possible that basal sliding may have moved the boreholes down-glacier to parts of the bed not affected by drilling. Borehole 89:2 was inspected $3 \mathrm{~d}$ after drilling and had a diameter of $15-20 \mathrm{~cm}$. Basal-sliding speed in this area is c. $2 \mathrm{~cm} \mathrm{~d}^{-1}$ (paper in preparation by R. LeB. Hooke, V.A. Pohjola, E. P. Jansson and J. Kohler). Thus, the borehole would have moved about $6 \mathrm{~cm}$ during this period, not sufficient to move away from the drilling site.

The bed was found to consist of soft, unconsolidated sediments. Most likely this was original bed material, since inspection of the borehole wall during lowering of the camera did not reveal enough englacial sediments to form a sediment layer of appreciable thickness. This suggests, either that originally deposited soft sediments were squeezed into the borehole from the bed or that more consolidated bed material became resedimented as a result of the drilling. The viewed upwelling of fines from the bed shows that the borehole was in contact with subglacial water but, according to the observed fine sediments, there could not have been any effective subglacial drainage at the bed of this borehole.

Borehole 89:3 was inspected 10d after drilling, and likewise had a diameter of $15-20 \mathrm{~cm}$. With a basal-sliding velocity of roughly $3 \mathrm{~cm} \mathrm{~d}^{-1}$ in this area (paper in preparation by R. LeB. Hooke, V.A. Pohjola, E. P. Jansson and J. Kohler), the borehole moved about $30 \mathrm{~cm}$ between drilling and inspection. This would have been enough to move the borehole away from its position during drilling. Even so, one cannot be sure that the observed bed was undisturbed. Borehole $89: 3$ had to be reamed from $162 \mathrm{~m}$ to the bed when the camera failed to reach the bed at the first attempt. During reaming, the drill was left for several minutes at the bed to enlarge the hole. This might have flushed original sediments away through a nearby subglacial meltwater channel exposed or created by the hot water.

Basal water movement was recorded towards the end of the camera observation of the bed, when a sediment cloud moved into the screen. The propagation of the cloud into the screen was c. $90 \mathrm{~mm} \mathrm{~h}^{-1}$ and this could be interpreted as if the bottom of the borehole was in contact with a subglacial drainage system. The observed water flux does not show any potential for an effective sediment transport system from the borehole bed. This negates the possibility that subglacial drainage would have washed out sediments after drilling action and, therefore, it seems probable that the viewed bed in borehole 89:3 was similar to the original bed.

\section{BASAL SLIDING}

\section{Measurements}

After inspection of borehole 89:3, the camera was left at the bed to record basal sliding of the glacier. The camera was suspended just above the bed and a cursor from the computer unit was initially fixed on a characteristic bed structure on the TV monitor. Camera movement over the glacier bed, shown on the monitor by the movement of the cursor along the bed, was recorded continously from 0925 to $1050 \mathrm{~h}$, a period of $90 \mathrm{~min}$, until visibility was lost 


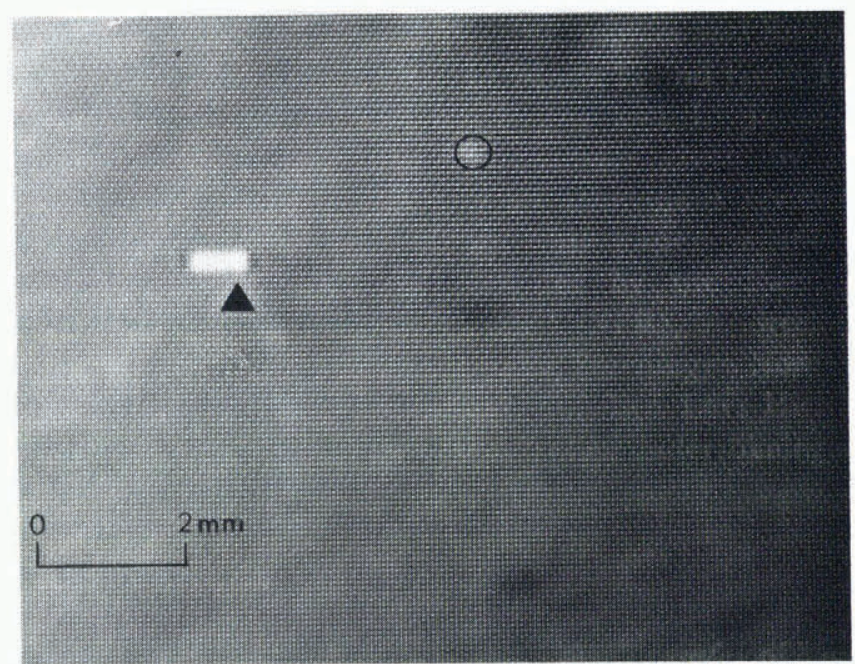

a

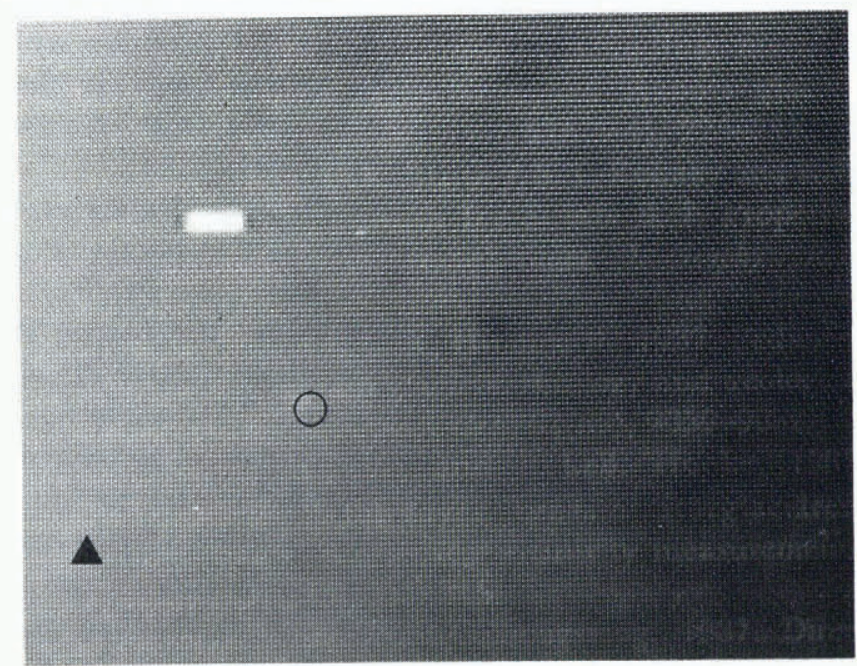

C

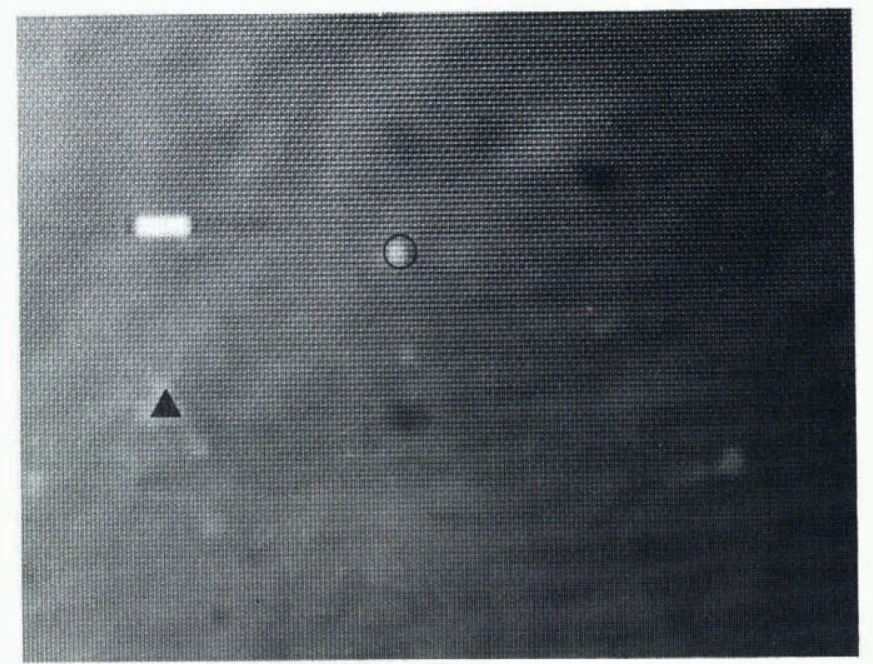

b

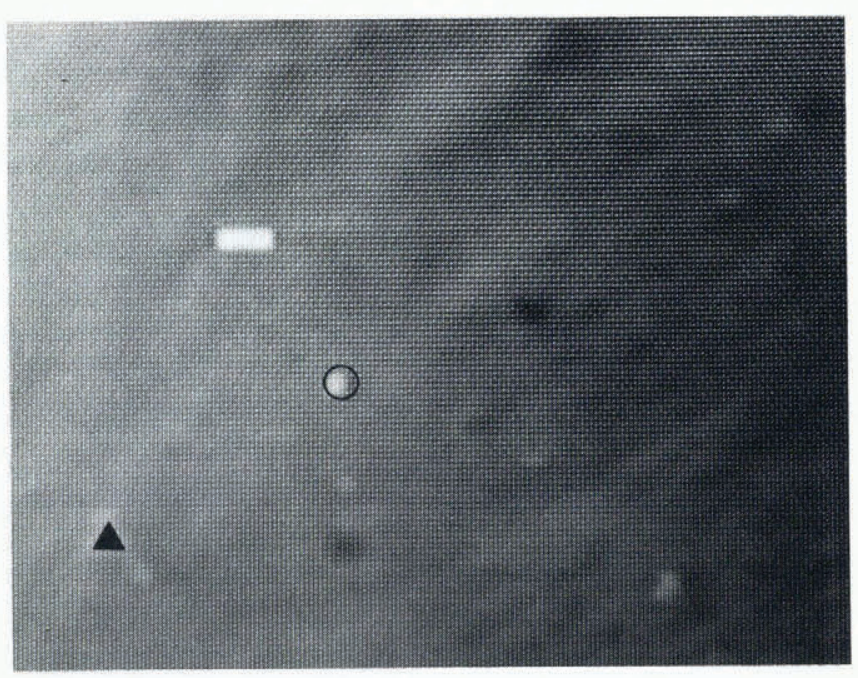

d

Fig. 3 a. $0930 \mathrm{~h}$. The bed in borehole 89:3 at the beginning of the basal sliding observation period. The white rectangular bar in the upper left of the picture is the cursor from the video computer, which was originally positioned just over the triangular mineral grain marked with a black triangle. b. 1000 h. This is just before the speed spike (see Fig. 5). c. $1030 \mathrm{~h} \mathrm{c.} 15 \mathrm{~min}$ after the end of the speed spike. $d .1045 \mathrm{~h}$. Flow of muddy basal water into the image from the lower left starts to obscure the view.

due to propagating cloudy bottom water. The movement was then quantified during replays of the scene by measuring the distance between the object and the cursor on the monitor screen. Figure $3 \mathrm{a}-\mathrm{d}$ shows images from four instants during the observation period.

In this experiment, the scale was positioned $2 \mathrm{~cm}$ from the viewing glass, and the camera was approximately $10 \mathrm{~cm}$ above the bed. At this height, the bed was enlarged 13 times on the monitor used for these measurements. The measurements were performed during four repeated replays to get a fair mean value of the camera movement. The mean total deviation in each measurement series from the mean value of a time interval from the four measurements was: $\pm 0.06,0.07,0.04$ and $0.02 \mathrm{~mm}$. This gives a maximum error in the measurements of $\pm 0.07 \mathrm{~mm} /$ time interval, which was approximately equal to the resolution of the monitor at this scale. Figure 4 shows the mean value of the four series of measured camera movement during the observation period.
The movement of the camera had two directions, a dominant direction during 14 of the intervals and a turn from that direction $70^{\circ}$ clockwise during two intervals ( $8 \mathrm{~min})$. The dominant direction of movement was assumed to be down-glacier; since it was impossible to use a compass, due to the steel pressure chamber, actual orientation of the movement is not known. Figure 5 shows the relative speed of the camera during 16 of the measured $5 \mathrm{~min}$ intervals, from 0930 to $1050 \mathrm{~h}$. The first minutes of the observed movement were rejected due to a higher degree of uncertainty in measurements. Total camera movement during the period was 5.57 $\pm 0.07 \mathrm{~mm}$.

The water level in the borehole rose $0.4 \mathrm{~m}$ between the beginning and the end of the inspection. It is possible that the increase in water pressure had an influence on the movement of basal water into the borehole at the end of the observation period. The water movement had approximately the same direction as the dominant direction of the camera movement; this is further 


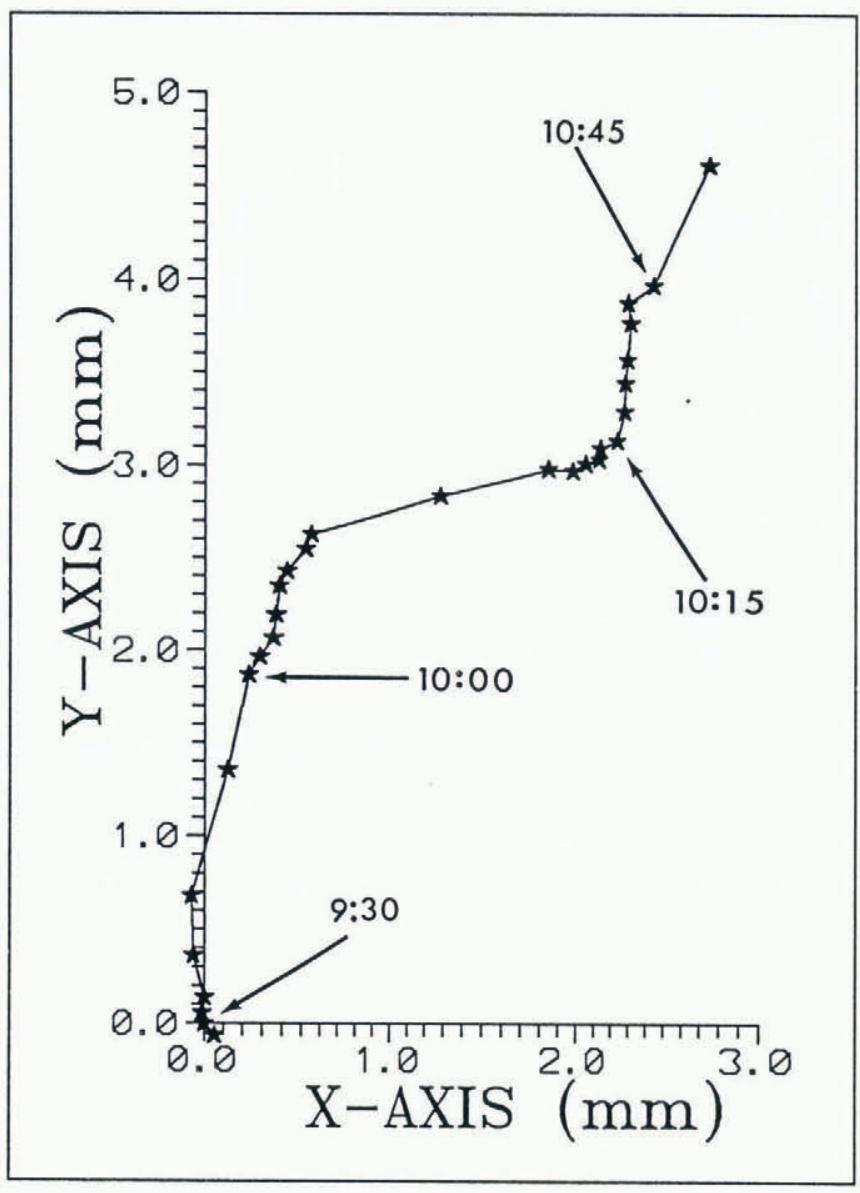

Fig. 4. Movement of a TV camera at the bed of borehole 89:3 between 0925 and $1050 \mathrm{~h}$. The movement was measured during four replays of the scene and the plot is a mean of those four measurements. The asterisks in the diagram symbolize the position of the camera within $1 \mathrm{~min}$ intervals between 1000 and $1015 \mathrm{~h}$ (reading for $1014 \mathrm{~h}$ is missing), and within $5 \mathrm{~min}$ intervals for the rest of the observation period. The reading for $0930 \mathrm{~h}$ is in the coordinates $(0,0)$.

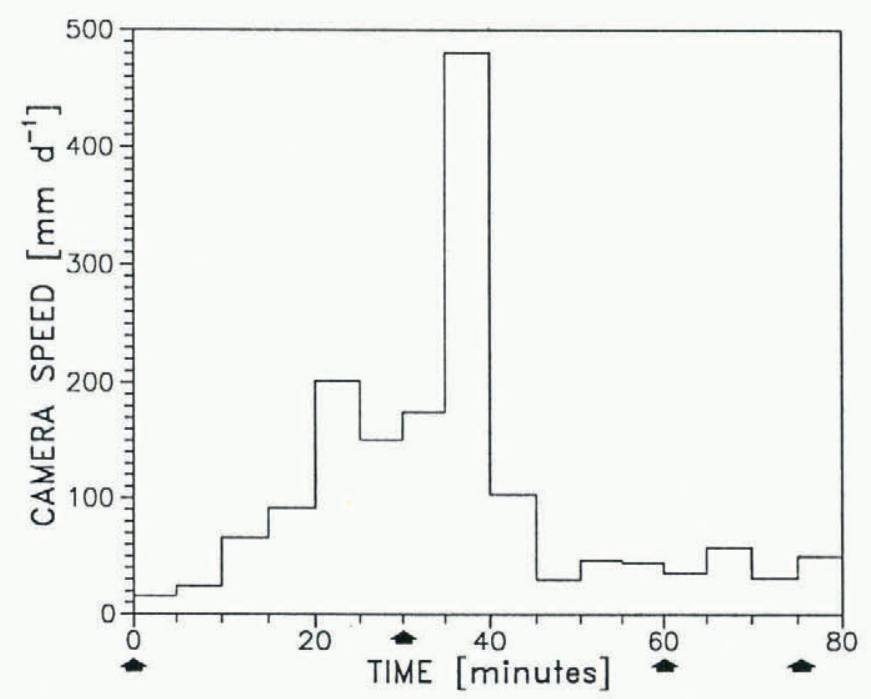

Fig. 5. Suggested basal-sliding speed measured in borehole 89:3 by a TV camera moving with the ice. The speed was measured during 5 min intervals and the plot is a mean of four replays of the scene. See also Figure 6 for a higher resolution of the time interval $30-45 \mathrm{~min}$. The heavy arrows mark when the photographs in Figure $3 a-d$ were taken. evidence for the suggestion that this direction was down-glacier.

\section{Discussion of error sources}

Can the recorded camera movement be considered to be synchronous with the sliding of the basal ice of the glacier? Studies of basal movements and basal sliding at the bed site of boreholes have been performed on Blue Glacier by Engelhardt and others (1978). They have revealed that the main problems with this type of observations were:

1. Contraction of the borehole, due to ice deformation.

2. Poor visibility, due to suspended sediment in the borehole.

3. Unstable bed, where they observed rolling clasts at the bed, due to the drag of the basal ice on the bed sediments.

\section{Anomalous strains acting on the basal ice.}

\section{Instability of the camera.}

The first of these problems was never encountered in this investigation of Storglaciären. The time of observation was limited to within a day and the water pressure in the borehole was high enough to suppress borehole closure. The second problem, regarding the visibility at the bottom of the borehole, was solved by Engelhardt and others (1978) by pumping clear water into the bottom of the borehole and hence lifting the muddy water from the area of observation. Unfortunately, there were no possibilities of managing any pumping during these investigations of Storglaciären, but it was possible to get close to the bed with the camera and, with access to good lighting, there was enough visibility to examine the bed. The third problem can be neglected in this investigation because the observed bed in borehole 89:3 was found to consist of bedrock.

Regarding the fourth problem, the effect of strains acting on the basal ice, it is believed to be very small. Measurements in a borehole, near borehole 89:3, showed that the internal deformation part of the ice movement varied between 5 and $8 \pm 5 \mathrm{~mm} \mathrm{~d}^{-1}$ during the ablation season (paper in preparation by R. LeB. Hooke, V.A. Pohjola, E. P. Jansson and J. Kohler). This small amount of internal deformation would not be able to affect the borehole tilt much over a period of $10 \mathrm{~d}$.

The fifth problem, the stability of the camera, is the most pertinent error source to discuss here. The recorded camera movement must be synchronous with the basal sliding, otherwise serious errors will occur in the interpretation of the measurements.

The best way to ensure that camera movement is synchronous with the basal ice movement is to stabilize the camera to the borehole wall with a frame of some kind. Such a frame was not available during these investigations but, during lowering of the camera in the borehole, it was seen that the borehole was off the vertical, by initial leaning, due to drilling or by internal 
deformation of the ice, so that the camera slid along the borehole wall. Even a small tilt of the borehole would be sufficient to cause this effect when the diameter of the borehole was just a few centimetres more then the diameter of the camera. The sliding of the camera along the borehole wall was seen from $111 \mathrm{~m}$ depth to $136 \mathrm{~m}$, where visibility disappeared.

By this, it is believed that the camera was hanging, with the camera cable in contact with the borehole wall, at least at $136 \mathrm{~m}$ depth, but probably closer to, or at, the bed.

Now, the fixation of the camera by direct contact of the chamber/ice at the bed, or cable/ice somewhere between the bed and $136 \mathrm{~m}$ depth, cannot be regarded as certain as a mechanical stabilizer, and the fifth problem can be subdivided into five sources of camera instability:

5.1. Camera not properly suspended above the bed and will, by this, be dragged along the bed.

5.2. A sudden force acting on the camera, which would set it into a pendular motion if the camera was not stabilized to the ice.

\subsection{Forces acting on the camera due to water movement.}

5.4. Displacement of camera, or camera cable, along the borehole wall during the survey, either directly by melting into the ice wall or indirectly, by a displacement of the wheel holding the camera cable at the ice surface due to ice melt or to a sudden force.

5.5. Vertical strain acting on the ice column during the measurements.

The first two sources of camera instability were controlled by (1) hoisting the camera some centimetres from the bed when it was reached; (2) observing if any pendular motion of the camera over the bed was visible during the inspection time interval, which was not the case.

The possibility of running water acting on the camera (3) can be regarded as being small. Basal water movement indicated by a cloud of suspended sediments, described at the end of the discussion of bed character, appeared at the end of the recorded period. This movement (c. $90 \mathrm{~mm} \mathrm{~h}^{-1}$ ) is considered to be too weak for any measurable impact on the camera stability and the camera did not show any increase in speed during this period (see Fig. 5). The water movement before the cloud appeared on the screen must be considered as much weaker due to the fact that the fine sediments, settled at the bed after the impact of the camera on the bed, was never put into any visible motion.

The fourth error source (4) was more difficult to prevent. The cable wheel was stabilized on the ice surface, but how effective that was is hard to estimate, and any possible displacements of camera/cable at the ice wall in the bottom of the borehole is even more difficult to determine. Anyway, if the cable wheel became dislodged on the surface, or camera/cable moved about, this should have been visible in the video record as a very sudden

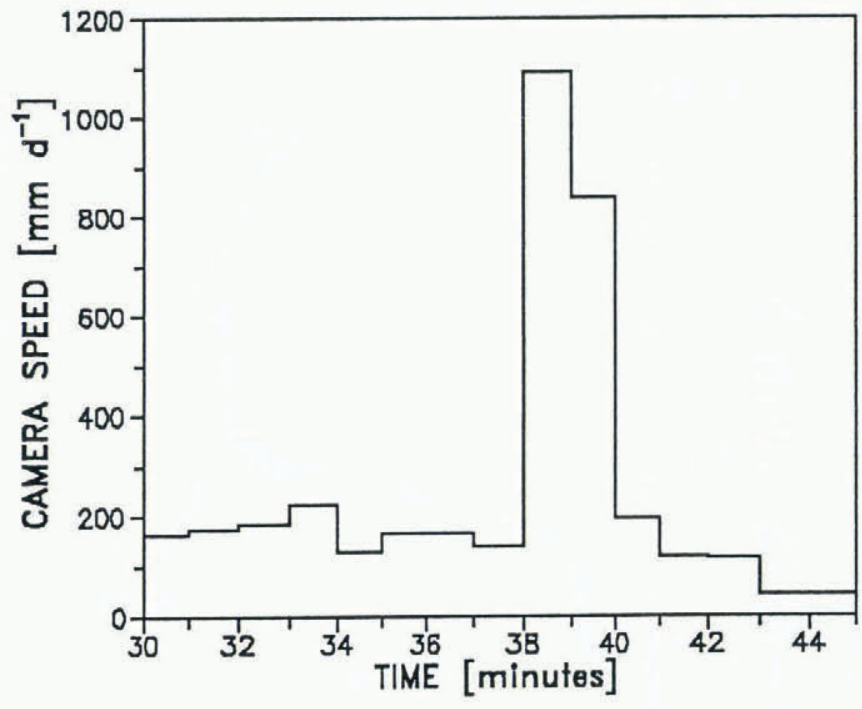

Fig. 6. Suggested basal-sliding speed measured in borehole 89:3 by a TV camera moving with the ice. This is a plot of the measured camera speed with the resolution of $1 \mathrm{~min}$ intervals during 15 min shown in Figure 5 as the three intervals $30-45 \mathrm{~min}$. The plot is a mean of four replays of the scene.

motion. To investigate whether the peak in the recorded speed during the interval between 35 and $40 \mathrm{~min}$ corresponded to any momentary movement of the camera, measurements at $1 \mathrm{~min}$ intervals were done. Figure 6 shows the measured camera speed between 30 and $45 \mathrm{~min}$ of recorded camera movement. In the figure it is shown that the peak in camera speed was spread over more than $2 \mathrm{~min}$. This is not interpreted as a sudden movement caused by a disturbed camera fix, as the peak interval is too broad for a sudden movement. The alternative interpretation of the camera-speed peak will be discussed later in the text.

Another possibility of instability of the camera is if the cable wheel, or the camera/cable, slowly melted itself down into the ice surface/ice wall during the measurement period. This would slowly lower the camera to the bed and can be confused with movement of the camera over the bed. If this spontaneous lowering happened, it should be recognized as a scale increase of the bed image on the monitor. No such scale change was found in the video record from this investigation.

The vertical strains (5) are very small in this part of Storglaciären (Hooke and others, 1989) and the error induced by vertical strains can be neglected during the short time span this observation deals with. Furthermore, if they acted on the ice column, this would also have been detected as a scale change of the bed image.

By this, there is no evidence of self-induced or false movements of the camera during the inspection and it is inferred that the recorded camera motion was largely synchronous with the basal ice movement.

\section{Discussion of the results}

How well does the suggested basal ice movement compare with earlier measurements of ice velocities on Storglaciären? Measurements of surface velocities on Storglac- 
iären (Hooke and others, 1983) showed an approximate annual mean velocity of $35 \mathrm{~mm} \mathrm{~d}^{-1}$ in the area of borehole $89: 3$, with daily means rising to $55 \mathrm{~mm} \mathrm{~d}^{-1}$. Inclinometry of a cased borehole in 1985 (paper in preparation by R. LeB. Hooke, V. A. Pohjola, E. P. Jansson and J. Kohler), in the same area as borehole 89:3, demonstrated that basal sliding over a period of several weeks was about $90 \%$ of the surface movement. It is interesting to note that the measured basal-sliding speed in borehole $89: 3$ has a "low mean value" of $37 \pm 20 \mathrm{~mm} \mathrm{~d}^{-1}$. The "low mean value" is the mean of measured speed when the high speed interval between 10 and $45 \mathrm{~min}$ is removed (see Fig. $5)$. This is within the range of the expected magnitude of basal sliding over a daily mean of surface velocity between 35 and $55 \mathrm{~mm} \mathrm{~d}^{-1}$.

Measurements in 1988 with an automatic distance measurer (MS thesis in preparation by G. Remple.) c. $100 \mathrm{~m}$ upstream from borehole 89:4 showed that the surface movement consisted of short high-velocity pulses. Averaged over $30 \mathrm{~min}$ intervals, Remple found velocity peaks of up to $100 \mathrm{~mm} \mathrm{~d}^{-1}$. These velocities are similar to the mean of the recorded speed of $100 \pm 20 \mathrm{~mm} \mathrm{~d}^{-1}$ measured over the $80 \mathrm{~min}$ interval in this investigation (see Fig. 5).

Seismic recordings of icequakes by L. G. Bäckström (personal communication) on Storglaciären in 1989 showed a high intensity of surfical icequakes in the area of borehole 89:3. This is a dynamically very active zone due to a bedrock riegel which transverses the bed. One can imagine that if data were available on surface movements by intervals of a few minutes, this quaking might be recorded as high-speed spikes, comparable to the maximum spike in basal speed of $480 \pm 20 \mathrm{~mm} \mathrm{~d}^{-1}$ detected in this investigation.

What then is the connection between surface-velocity spikes and spikes in basal-sliding speed? In a theoretical study of the transfer of basal-sliding variations through linearly viscous ice to the surface, Balise and Raymond (1985) found that the extent to which the disturbance would be recognized at the surface was dependent upon the scale of the disturbance at the bed. At very small scales (length of disturbance much less than ice depth), the disturbance of a single event was totally attenuated at the surface. However, closely repeated disturbances in time or space could succeed in being transferred to the surface.

The high-velocity spikes observed in borehole 89:3 seem to be superimposed on a background sliding speed. As the "lower mean sliding speed" found in this study is in the range of the expected sliding speed, it may be interpreted as a steady-state motion. This may reflect the fact that basal-sliding speed consists of two parts: a steady-state motion and a jerky motion induced by occasional stress releases. These stress-release events result from ice slippage over small-scale irregularities at the bed, and cause spikes of the kind shown in Figure 6. This produces a high signal locally. With time and space, the signal will be attenuated and unrecognizable in the steady-state motion.

Stress releases are also likely to be widespread and they are assumed to be strongly dependent on irregularities of the bed topography. This would result in motions with different orientations at any given point on the bed, reflecting the direction and distance from, and strength of the actual centre of stress release. This can explain the sudden swing in direction during the speed spike shown in Figure 4.

The results of Engelhardt and others (1978), in which they photographed a glacier bed through boreholes during short intervals repeated over several years, could be interpreted as influenced by these bed-controlled stress releases. They found no spatial correlation in basal sliding speed between different boreholes and no correlation in time of basal sliding speed in the same borehole (Engelhardt and others, 1978, p. 499). A similar pattern was found by Hagen and others (1983) when they recorded large local variations in ice movement along the glacier sole with pressure gauges at the bed of Bondhusbreen.

From this, it seems probable that the recorded camera speed was fairly synchronous with the basal sliding of the glacier. Basal sliding must have occurred during the observation period. As the observed camera speed was reasonably comparable to the basal-sliding velocity in this region, as inferred by other methods, it seems improbable that basal sliding would be completely masked by random camera movement.

\section{CONGLUSIONS}

It is possible to record basal sliding continuously using borehole $\mathrm{TV}$, although there are difficulties in handling and controlling camera stability. It is inferred that the recorded movement of the camera was synchronous with the basal sliding of the glacier, as recorded basal-sliding speed is comparable to speeds observed by other methods. From this observation, it is also suggested that sudden stress releases over bed irregularities are superimposed on a lower background basal sliding and that sudden stress releases have a major effect on basal sliding over a small area during short time spans.

The bed observed with the video camera in the two boreholes consisted of different material; one borehole appeared to be over a soft-sediment bed, the other over a rock bed. These findings are consistent with earlier investigations of the bed, suggesting that both bare rock and sediments underlie the overdeepening of Storglaciären. The fact that both bed types were observed was probably coincidental; there is still insufficient information to predict the areal extent or position of the two bed types. With regard to the sliding observation, a rock bed of some extent is evident around borehole 89:3. A soft-sediment bed would probably not provide necessary bed roughness to produce the observed jerky motion of the basal sliding.

\section{ACKNOWLEDGEMENTS}

My sincere thanks are due to all persons and organizations who gave me stimulation to, and invaluable assistance with, this work. In particular, thanks are due to: Professor R. LeB. Hooke, P. Jansson and J. Kohler, University of Minnesota; Professor T. Stenborg, Uppsala Universitet; Professor W. Karlén, Stockholms Universitet; 
Dr M. Kennett, Norwegian Water Resources and Energy Administration (NVE), Oslo; D. Moen, Eivind Koch TV Rørinspeksjon A/S, Oslo; S. Troëng and L. Jonsson, Tarfala Research Station. The advice given by $\mathrm{K}$. Echelmeyer, W. Harrison and an anonymous reviewer regarding the final draft of this paper is much appreciated. Funds were provided by the Swedish Natural Science Research Council (NFR), Andreéfonden, Helge Ax:son Johnsons stiftelse, Föreningen Norden, Axel Hambergs testamentesfond, Stiftelsen Lars Hiertas minne and STF:s fond för vetenskapliga undersökningar.

\section{REFERENCES}

Balise, M.J. and C. F. Raymond. 1985. Transfer of basal sliding variations to the surface of a linearly viscous glacier. J. Glaciol., 31(109), 308-318.

Björnsson, H. 1981. Radio-echo sounding maps of Storglaciären, Isfallsglaciären and Rabots glaciär, northern Sweden. Geogr. Ann., 63A(3-4), 225-231.

Blankenship, D. D., C. R. Bentley, S. T. Rooney and R. B. Alley. 1987. Till beneath Ice Stream B. I. Properties derived from seismic travel times. 7. Geophys. Res., 92(B9), 8903-8911.

Boulton, G. S. and R. C. A. Hindmarsh. 1987. Sediment deformation beneath glaciers: rheology and geological consequences. 7. Geophys. Res., 92(B9), 9059-9082.

Brand, G., V. Pohjola and R. LeB. Hooke. 1987. Evidence for a till layer beneath Storglaciären, Sweden, based on electrical resistivity measurements. 7. Glaciol., 33(115), 311-315.

Echelmeyer, K. and Wang Zhongxiang. 1987. Direct observation of basal sliding and deformation of basal drift at sub-freezing temperatures. F. Glaciol., 33(113), 83-98.

Engelhardt, H. F, W.D. Harrison and B. Kamb. 1978. Basal sliding and conditions at the glacier bed as revealed by bore-hole photography. F. Glaciol., 20(84), 469-508.

Haeberli, W. and W. Fisch. 1984. Electrical resistivity soundings of glacier beds: a test study on Grubengletscher, Wallis, Swiss Alps. F. Glaciol., 30(106), 373376.

Hagen, J. O. 1986. Glasiale prosesser ved utvalgte breer. Oslo, Universitetet i Oslo. Geografisk Institutt. (Meddelelser. Naturgeografisk Serie. Rapport 4.)

Hagen, J. O., B. Wold, O. Liestøl, G. Østrem and J.L. Sollid. 1983. Subglacial processes at Bondhusbreen,
Norway: preliminary results. Ann. Glaciol., 4, 91-98.

Harrison, W. D. and B. Kamb. 1973. Glacier bore-hole photography. 7. Glaciol., 12(64), 129-137.

Holmlund, P. 1987. Mass balance of Storglaciären during the 20th century. Geogr. Ann., 69A(3-4), 439-447.

Holmlund, P. 1988. Is the longitudinal profile of Storglaciären, northern Sweden, in balance with the present climate? f. Glaciol., 34(118), 269-273.

Holmlund, P. and M. Eriksson. 1989. The cold surface layer on Storglaciären. Geogr. Ann., 71A(3-4), 241-244.

Hooke, R. LeB., J. Brzozowski and C. Bronge. 1983. Seasonal variations in surface velocity, Storglaciären, Sweden. Geogr. Ann., 65A(3-4), 263-277.

Hooke, R. LeB., P. Holmlund and N. R. Iverson. 1987. Extrusion flow demonstrated by bore-hole deformation measurements over a riegel, Storglaciären, Sweden. J. Glaciol., 33(113), 72-78.

Hooke, R. LeB., S.B. Miller and J. Kohler. 1988. Character of the englacial and subglacial drainage system in the upper part of the ablation area of Storglaciären, Sweden. J. Glaciol., 34(117), 228-231.

Hooke, R. LeB., P. Calla, P. Holmlund, M. Nilsson and A. Stroeven. 1989. A 3 year record of seasonal variations in surface velocity, Storglaciären, Sweden. 7. Glaciol., 35(120), 235-247.

Hooke, R. LeB., T. Lauman and J. Kohler. 1990. Subglacial water pressures and the shape of subglacial conduits. 7. Glaciol., 36(122), 67-71.

Jansson, P. and R.LeB. Hooke. 1989. Short-term variations in strain and surface tilt on Storglaciären, Kebnekaise, northern Sweden. 7. Glaciol., 35(120), 201-209.

Koerner, R. M., D. A. Fisher and M. Parnandi. 1981. Bore-hole video and photographic cameras. Ann. Glaciol., 2, 34-38.

Schytt, V. 1962. Naturgeografisk fältstation i Kebnekajse. Sven. Naturvetensk. 1962, 332-345.

Schytt, V. Unpublished. Tarfala och dess forskningsverksamhet. Stockholms Universitet. Naturgeografiska Fältstationen i Tarfala.

Theakstone, W. H. 1979. Observations within cavities at the bed of the glacier Østerdalsisen, Norway. $\mathcal{F}$. Glaciol., 23(89), 273-281.

Walford, M. E. R., M.I. Kennett and P. Holmlund. 1986. Interpretation of radio echoes from Storglaciären, northern Sweden. J. Glaciol., 32(110), 39-49.

The accuracy of references in the text and in this list is the responsibility of the author, to whom queries should be addressed. 